\title{
Necessidades de saúde de camponeses em conflito ambiental frente à instalação de Perímetros Irrigados
}

\author{
Health needs of the rural population in environmental conflict \\ due to the installation of Irrigated Perimeters
}

Andrezza Graziella Veríssimo Pontes ${ }^{1}$

Raquel Maria Rigotto ${ }^{2}$

Jennifer Vale Silva ${ }^{3}$

${ }^{1}$ Departamento de Enfermagem, Faculdade de Enfermagem, Universidade do Estado do Rio Grande do Norte (UERN). R. Dionísio Figueira 383, Centro. 59610090 Mossoró RN Brasil.

andrezzagazi@hotmail.com ${ }^{2}$ Departamento de Saúde Comunitária, Faculdade de Medicina, Universidade Federal do Ceará. Fortaleza CE Brasil.

${ }^{3}$ Departamento de Ciências Biomédicas, Faculdade de Ciências da Saúde, UERN. Mossoró RN Brasil.

\begin{abstract}
The transformations in the Brazilian agricultural scenario have reconfigured lifestyles in the countryside, with repercussions on the health of the rural population. The scope of this paper is to analyze health needs of farmers, identified by a collective of university actors, the Unified Health System and social movements. It is action-research, with a group comprised of community health workers, workers in a Reference Center in Occupational Health, a university professor and representatives of social movements. Semi-structured interviews and field visits were conducted, as well as workshops and seminars. The thematic categorization revealed five health need groupings: the need for revision of the agrarian development model; the need for good living conditions; the need for social mobilization; the need to avoid the use of pesticides; and the need for action of the Unified Health System (SUS). The dialogue of knowledge and exchange of experience elicited the recognition of health needs that require intersectoral action. Health needs must be understood in the context of the territories to which the individuals and groups belong, acknowledging the complexity of social, economic, cultural and environmental issues.
\end{abstract}

Key words Needs and demands of health services, Environmental health, Worker health, Health of rural populations, Public policies
Resumo As transformações no cenário agrícola brasileiro vêm reconfigurando os modos de vida no campo, com repercussões sobre a saúde da população camponesa. Objetiva-se analisar necessidades de saúde de camponeses, identificadas por um coletivo de atores da universidade, Sistema Único de Saúde e movimentos sociais. Pesquisa-ação, cujo grupo foi constituído por agentes comunitários de saúde, trabalhadores de Centro de Referência em Saúde do Trabalhador, professor universitário e representantes de movimentos sociais. Realizaram-se entrevistas semiestruturadas, visitas em campo, oficinas e seminários. A categorização temática evidenciou cinco conjuntos de necessidades de saúde: de revisão do modelo de desenvolvimento agrário, de boas condições de vida, de mobilização social, de evitar uso de agrotóxicos e de atuação do SUS. O diálogo de saberes e a troca de experiência potencializaram o reconhecimento de necessidades de saúde que requerem ações intersetoriais. As necessidades de saúde devem ser compreendidas no contexto dos territórios em que os sujeitos individuais e coletivos se inserem, reconhecendo-se a complexidade das questões sociais, econômicas, culturais e ambientais.

Palavras-chave Necessidades e demandas de serviços de saúde, Saúde ambiental, Saúde do trabalhador, Saúde das populações rurais, Políticas públicas 


\section{Introdução}

As implicações negativas do desenvolvimento capitalista para o trabalho, o ambiente e a saú$\mathrm{de}^{1-4}$, bem como a distribuição desigual dos seus riscos e danos no planeta, destinados, sobretudo, às populações mais vulneráveis, pobres e discriminadas da sociedade ${ }^{4}$, vêm sendo evidenciadas em diversos estudos da Saúde Coletiva.

A intensificação da forma capitalista de produzir na agropecuária promoveu reestruturação produtiva e territorial no setor ${ }^{5}$, denominada modernização agrícola, com o agronegócio como um forte elemento ${ }^{6}$. Agronegócio é um complexo de sistemas que compreende agricultura, indústria, mercado e finanças. O movimento desse complexo e suas políticas formam um modelo de desenvolvimento econômico controlado por corporações transnacionais, que trabalham com um ou mais commodities e atuam em diversos outros setores da economia ${ }^{7}$. A expansão do agronegócio, em todo o mundo, foi impulsionada pela Revolução Verde, que trouxe três importantes mudanças tecnológicas no processo de produção agrícola: a mecanização de diversas atividades, a introdução dos agrotóxicos a partir de 1930, e a introdução da biotecnologia ${ }^{8}$.

Entre as implicações do agronegócio para o trabalho, o ambiente e a saúde no território em que se instala, destacam-se: a concentração de terras e os deslocamentos compulsórios da população; a violência; o comprometimento da segurança alimentar; mudanças nas práticas sociais e laços de vida comunitária; imposição de novos hábitos culturais; mudanças na dinâmica de cidades vizinhas, com a formação de "favelas" rurais; uso intensivo de novas tecnologias de mecanização e de insumos (fertilizantes e agrotóxicos); relações e condições de trabalho precarizadas com baixa remuneração; descumprimento da legislação trabalhista; intensificação do trabalho; exposição a situações de risco à saúde; redução da biodiversidade e dos serviços ambientais; degradação do solo pela monocultura e risco de desertificação; elevado consumo de água; contaminação do ar e de águas superficiais e subterrâneas por fertilizantes e agrotóxicos; exposição das comunidades do entorno das fazendas à contaminação pelos agrotóxicos utilizados de forma intensiva ${ }^{6}$.

O modelo de desenvolvimento agrário pautado no agronegócio é diferente do baseado na agricultura familiar camponesa. No primeiro, a monocultura, o trabalho assalariado e a produção em grande escala são algumas das principais referências. Já no segundo é caracterizado pela biodiversidade, predominância do trabalho familiar e produção em pequena escala ${ }^{7}$. A agricultura familiar camponesa, na perspectiva agroecológica, constitui alternativa de modelo de desenvolvimento que tem seu processo de produção fundado "na diversidade produtiva, em economia de escopo, em territórios política e socialmente estabelecidos, e é viabilizada pelo encurtamento das cadeias de produção e comercialização". A agroecologia contribui para a promoção da saúde e da segurança alimentar', e vai além da não utilização de agrotóxicos. Alguns dos seus pilares são o respeito, o resgate e a valorização dos conhecimentos de agricultores(as), em processo de inovação orientados para a promoção de ecossistemas agrícolas mais sustentáveis ${ }^{10}$.

As políticas agrícolas, no semiárido do país, desde os anos 1960, como estratégia geopolítica de indução do desenvolvimento, vêm acompanhadas da implantação de perímetros públicos irrigados ${ }^{6}$, definidos como áreas delimitadas pelo Estado para execução de projetos públicos de agricultura irrigada, as quais, em geral, possuem significativo potencial agricultável, caracterizado por solos férteis, presença hídrica, clima favorável e abundante força de trabalho. Esses elementos, conjugados às infraestruturas implementadas, como canais e piscinas, favorecem ampla produtividade agrícola ${ }^{11}$.

A imposição de projetos de irrigação, pelo Estado, está associada à instalação de empresas do agronegócio nesses locais, o que representa uma ampla cadeia de perdas, impactos e danos às populações do campo, que têm seus modos de vida tradicionais ameaçados pelas transformações impostas aos territórios em que vivem e trabalham $^{12}$. Nesse contexto, intensificam-se conflitos ambientais distributivos, com graves desigualdades sociais em torno do acesso aos recursos naturais e da utilização destes; espaciais, causados por efeitos ou impactos ambientais que ultrapassam os limites entre os territórios de diversos agentes ou grupos sociais, tais como emissões gasosas, poluição da água, entre outros; e territoriais, frutos de disputas entre grupos com modos distintos de apropriação ou produção do espaço ${ }^{13}$.

Os conflitos e problemas sociais constituídos nesse cenário geram diversas necessidades de saúde, entendidas como sociais porque são determinadas sócio-historicamente; revelam necessidades de sujeitos que estabelecem relações sociais com outros sujeitos ${ }^{14}$. Ao mesmo tempo, expressam a manifestação consciente desses sujeitos de que lhes falta alguma coisa e, por isso, 
também, servem-lhes de motivação na medida em que essa falta os estimula a preenchê-las ${ }^{15}$.

A identificação das necessidades de saúde é imprescindível à atuação do Sistema Único de Saúde (SUS), seja de forma autônoma e/ou em articulação com outras políticas sociais. Deve ocorrer de forma participativa, incluindo os sujeitos portadores das necessidades, o que possibilita tornar visíveis necessidades não capturáveis pelo olhar, exclusivamente, técnico, de natureza clínica ou epidemiológica. Ademais, tem permitido conformar problemas mais sintonizados com um conceito ampliado de saúde, tal como preconiza o SUS, não se restringindo a demandas por serviços médicos ${ }^{16,17}$.

Em município de pequeno porte do Nordeste brasileiro, comunidades camponesas desenvolvem um modo de vida em convivência com o semiárido, mediante a agricultura familiar, com que se afina, em grande parte, a proposta agroecológica. Através disso, construíram valores, costumes e culturas distintos da lógica capitalista do agronegócio. Entretanto, esse modo de vida encontra-se ameaçado pela instalação de um projeto de irrigação. Nesse cenário, existe um conflito ambiental de caráter territorial e distributivo, materializado contra essa instalação, o agronegócio e os agrotóxicos, em defesa do acesso igualitário à água para a agricultura familiar camponesa e da afirmação do modo de vida supracitado. Emergem aí ações de resistência dos camponeses, com apoio de movimentos sociais, instituições e atores da universidade ${ }^{18}$. Nesse sentido, o presente artigo objetiva analisar as necessidades de saúde de camponeses em contexto de conflito ambiental, identificadas por meio da articulação de sujeitos da universidade, do SUS e de movimentos sociais.

\section{Metodologia}

Pesquisa de enfoque qualitativo ${ }^{19}$, cujo desenho de estudo adotado foi a pesquisa-ação, definida como "um tipo de pesquisa social com base empírica que é concebida e realizada em estreita associação com uma ação ou com a resolução de um problema coletivo e no qual os pesquisadores e participantes representativos da situação ou do problema estão envolvidos de modo cooperativo e colaborativo" 20 .

A pesquisa foi realizada no município Apodi, no Estado do Rio Grande do Norte, particularmente, no território camponês denominado Chapada do Apodi, constituído por 45 comu- nidades, que totalizavam 1649 famílias residentes. O Perímetro Irrigado Santa Cruz do Apodi pretende levar água da Barragem Santa Cruz, por meio de canais de irrigação, para as plantações de empresas do agronegócio que irão se instalar no território da Chapada do Apodi-RN, afetando as comunidades aí residentes.

O grupo da pesquisa-ação constituiu-se de pessoas da universidade, do SUS e dos movimentos sociais, mediante os critérios de inclusão: da universidade - ser docente das universidades públicas mais próximas do local de estudo e de áreas com ligação direta ou indireta com a temática; do SUS - trabalhadores do serviços públicos de saúde do município de estudo e das instâncias de saúde do trabalhador (Centro de Referência em Saúde do Trabalhador - CEREST regional - e Núcleo Regional de Saúde do Trabalhador - NURSAT) que tivessem o local de estudo como área de abrangência de trabalho; dos movimentos sociais - os que estivessem interessados e/ou envolvidos com o conflito ambiental. O grupo foi composto por seis Agentes Comunitários de Saúde (ACS) de uma equipe da Estratégia Saúde da Família (ESF), dois trabalhadores do CEREST, dois representantes do Sindicato dos Trabalhadores e Trabalhadoras Rurais (STTR), um da Comissão Pastoral da Terra (CPT) e um professor universitário do curso de Agronomia, o que totalizou 12 participantes. Registra-se que a pesquisa foi aprovada pelo Comitê de Ética na Pesquisa (COMEP) da Universidade Federal do Ceará.

Realizaram-se seis encontros do grupo de pesquisa, ocorridos quinzenalmente, com duração de oito horas cada um e com as seguintes atividades: no primeiro, houve formação do grupo, apresentação dos participantes, exposição de expectativas, pactuação de cronograma, atividades e compromissos; no segundo, estudo de campo, entrevistas semiestruturadas com moradores, momentos de discussão com professores e extrabalhadores do agronegócio em outro município, com experiência anterior de substituição da agricultura familiar pelo agronegócio; no terceiro, estudos de campo nas comunidades pesquisadas, com visita in loco e discussão com camponeses residentes; no quarto, oficina com o grupo de pesquisa para discutir os estudos de campo e sistematizar as informações, do que resultaram a compreensão e caracterização das inter-relações entre produção-trabalho-ambiente-saúde nos territórios estudados; no quinto, oficina para identificar as necessidades de saúde das comunidades camponesas e realização de seminários; e, no sexto, oficina de construção coletiva de um 
plano de ação para atender as necessidades de saúde identificadas e contribuir com a saúde do trabalhador e ambiental. $\mathrm{O}$ trabalho de campo e o diálogo entre os sujeitos, nas discussões do grupo, promoveram troca de experiências que contribuiu para a construção coletiva de um olhar crítico sobre o contexto das relações produçãotrabalho-ambiente-saúde e as necessidades de saúde no território investigado.

Os encontros foram gravados, transcritos e analisados, o que permitiu identificar as categorias analíticas "necessidades de saúde de comunidades camponesas" e "resposta a essas necessidades". A análise considerou: as necessidades expressas pelas comunidades camponesas no terceiro encontro; as necessidades de saúde percebidas pelo grupo de pesquisa durante todo o percurso metodológico e nas oficinas de sistematização do quarto encontro e de identificação das necessidades no quinto. A partir disso, através do exercício da hermenêutica e em diálogo com o referencial teórico construído, tentou-se fazer um movimento de articulação das partes para o todo e do todo para as partes, e emergiram cinco subcategorias empíricas: necessidade de revisão do modelo de desenvolvimento agrário; de boas condições de vida; de mobilização social; de evitar uso de agrotóxicos; de atuação do SUS. O plano de ação construído pelo grupo de pesquisa foi analisado na perspectiva de dar resposta a essas necessidades.

\section{Resultados e discussão}

As necessidades de saúde identificadas foram agrupadas em cinco conjuntos, sintetizados no Quadro 1.

\section{Necessidade de revisão do modelo de desenvolvimento agrário}

A necessidade de revisão do modelo de desenvolvimento agrário brasileiro se contextualiza diante do conflito ambiental vivenciado, cujo cerne da questão é a disputa pelos modelos de desenvolvimento para o território camponês: um pautado no agronegócio versus outro pautado na agricultura familiar camponesa, na perspectiva agroecológica.

"A primeira questão é: 'Por que contestar o projeto de irrigação da Chapada do Apodi'? Geralmente, o pessoal diz que a gente é que tem sido até antiquado nos nossos dizeres. Por que, 'ora, não querer o desenvolvimento para o nosso município?' Mas que desenvolvimento é esse que traz doenças, que traz mazelas para quem está lá, no campo? A Chapada do Apodi, da parte que compreende o Ceará, está sendo alvo de inúmeros problemas sociais e ambientais trazidos pelo agronegócio. E, aqui, a gente tem como anteceder esses fatos. Então, não se pode aceitar um projeto de irrigação baseado numa ótica de desenvolvimento totalmente contraditória para a realidade local. São essas experiências que o DNOCS acumula no que diz respeito à execução de projetos de irrigação no Nordeste. A gente tem que viver nossa vida bem e com saúde. Nós, que somos agricultores, a gente quer é viver com saúde, lazer, em paz, nas nossas terras. No município de Apodi, a gente tem a questão do manejo da caatinga, a apicultura, que é muito forte, a caprinocultura, a questão das hortaliças orgânicas, a agricultura de sequeiro, a questão da produção de polpas de fruta, que também existe, e os quintais produtivos, que é a questão de você ter, nos seus quintais, a galinha, um canteirozinho, uma coisa toda que vai vivendo bem ali, com saúde e dignidade" (Movimentos Sociais).

Nesse contexto, as comunidades camponesas, presentes no encontro com o grupo de pesquisa, quando indagadas sobre o que precisavam para ter saúde, responderam a não instalação do projeto de irrigação e comentaram ainda que esse era o principal problema de saúde que estavam enfrentando:

Poderemos evitar, primeiro do que tudo, isso que está vindo [projeto de irrigação]. Isso é a nossa maior preocupação: que os perímetros irrigados, eles acabam com a saúde do povo vizinho. Nós estamos nessa luta. Também, se aquela empresa [do agronegócio] saísse de lá, era bom para nossa saúde, para o nosso assentamento (Camponeses). (Grifos nossos).

Essa necessidade demonstra a importância de o SUS, e, em especial, a ESF, olhar para o território e ouvir o que a população expressa ser sua necessidade de saúde. Caso contrário, corre-se o risco de atuar sobre os programas que o Ministério da Saúde determina, sem visualizar o contexto histórico dos territórios, como vivem e trabalham as pessoas e quais seus problemas e necessidades de saúde.

$\mathrm{O}$ atendimento a essa necessidade está diretamente relacionado à atuação do Estado, requer intervenção política em torno do modelo de desenvolvimento agrário brasileiro. "Entre todas as mediações sociais que condicionam a reprodução dos processos vitais dos indivíduos, a mais importante, para superar as dificuldades impos- 
Quadro 1. Necessidades de saúde de camponeses ${ }^{18}$.

\begin{tabular}{|c|c|}
\hline $\begin{array}{l}\text { Necessidade de } \\
\text { revisão do modelo } \\
\text { de desenvolvimento } \\
\text { agrário }\end{array}$ & $\begin{array}{l}\text { - Evitar o projeto de irrigação. } \\
\text { - Tirar a empresa do agronegócio que já existe, ou convencê-la a produzir de outra } \\
\text { forma. }\end{array}$ \\
\hline $\begin{array}{l}\text { Necessidade de boas } \\
\text { condições de vida }\end{array}$ & $\begin{array}{l}\text { - Melhorar as condições gerais de vida: moradia, saneamento básico, trabalho, } \\
\text { transporte, estradas, educação, etc. } \\
\text { - } \quad \text { Ter dinheiro. }\end{array}$ \\
\hline $\begin{array}{l}\text { Necessidade de } \\
\text { mobilização social }\end{array}$ & $\begin{array}{l}\text { - Fortalecer os movimentos sociais para as ações contrárias ao "Projeto". } \\
\text { - Conscientizar as pessoas para evitar o projeto de irrigação. } \\
\text { - Estimular os trabalhadores do agronegócio já existente a lutarem por seus } \\
\text { direitos. } \\
\text { - Estimular as comunidades camponesas a lutarem por seus direitos sociais básicos. }\end{array}$ \\
\hline $\begin{array}{l}\text { Necessidade de evitar } \\
\text { os agrotóxicos }\end{array}$ & $\begin{array}{l}\text { - Deixar de usar agrotóxicos e de comer com eles. } \\
\text { - Conscientização de crianças, comunidades camponesas, trabalhadores do } \\
\text { agronegócio e agricultores familiares sobre os riscos dos agrotóxicos. }\end{array}$ \\
\hline $\begin{array}{l}\text { Necessidade de atuação } \\
\text { do SUS }\end{array}$ & $\begin{array}{ll}\text { - } & \text { Melhorar a gestão dos serviços de saúde. } \\
\text { - } & \text { Trabacitar os trabalhadores do SUS. } \\
\text { - } & \text { Melhorar o acesso ao SUS. } \\
\text { - } & \text { Atuação efetiva do PSF. } \\
\text { - } & \text { Rearantir atenção integral à saúde. } \\
\text { - } & \text { Realizar vigilância de Saúde do Traúde. } \\
\text { - } & \text { Realizar promoção da saúde. } \\
\text { - } & \text { Realizar prevenção de doenças e agravos. } \\
\text { - } & \text { Realizar educação em saúde. }\end{array}$ \\
\hline
\end{tabular}

tas a essa reprodução, é, sem dúvida, a forma de ordenamento político da sociedade" ${ }^{\text {"17. }}$.

Na sociedade capitalista contemporânea, esse ordenamento é contraditório devido ao próprio paradoxo do Estado, pois este, através do DNOCS, impõe um modelo de desenvolvimento agrário de incentivo ao agronegócio. E esse mesmo Estado, como SUS, é responsável por garantir o direito à saúde. Tal contradição é assim percebida pelo grupo de pesquisa:

Que espécie de governo é esse que dá com uma mão e puxa com a outra? Porque um governo que quer melhorar a condição de vida das famílias e, ao mesmo tempo, permite um projeto desse [de irrigação], que vem para cá para impactar. Porque isso aí não vai causar o impacto só no meio ambiente, não; e na vida das pessoas. Tem pessoas que não dormem mais de noite, imaginando sair das suas casas. Isso aí a gente tem que visualizar também (ACS). (Grifos nossos).

\section{Necessidade de boas condições de vida}

A relação entre condições de vida e saúde é bem conhecida no campo da Saúde Coletiva.
Remonta ao nascimento da Medicina Social, associados à qual se podem citar, ainda no século XIX, os trabalhos de Rudolf Vichow e Frederich Engels, evidenciando a relação entre as condições de vida e trabalho da população europeia e sua saúde $^{21,22}$. Na segunda metade do século XX, na América Latina, essa compreensão foi central ao corpo de conhecimentos que originaram a Epidemiologia Social e a Saúde Coletiva ${ }^{23-25}$ e teve papel fundamental nos anos de 1970 e 1980, como alicerce conceitual da reforma sanitária brasileira $^{26}$.

A necessidade de boas condições de vida remete a melhorias de educação, incentivo à agricultura familiar camponesa, habitação, saneamento básico, transporte, estradas, trabalho digno, entre outras questões sociais.

A redução de investimentos do Estado em políticas sociais tem um impacto, significativamente, mais negativo nas populações do campo. Estas vivem, geralmente, em precárias condições de vida, com limitações de acesso às políticas públicas $^{27}$. O Plano Safra tem destino, atualmente, entre 80 e $90 \%$ do orçamento para o financiamento do agronegócio, e a parcela restante fica 
para a agricultura familiar' ${ }^{9}$ Essa realidade nacional é sentida pelos camponeses da Chapada do Apodi-RN, os quais relatam, mesmo diante de suas potencialidades, enfrentarem dificuldades, conforme fala a seguir:

A burocracia no acesso ao crédito e a comercialização dos produtos dos agricultores é muito difícil. São estradas também, porque, sem estradas, a gente também não comercializa nada. Até mesmo no caso de problemas de saúde, se você adoecer, pode ir até a óbito. Moradias inadequadas, porque ainda tem muita gente morando em casa de taipa. A falta de saneamento básico. Pessoas que ainda defecam em céu aberto, porque não têm sanitário na casa, não têm banheiro. Não têm coletora de lixo, o lixo é jogado a céu aberto. Educação, também, é uma das dificuldades. Os estudantes vêm em cima de um pau de arara para estudar. E acesso à saúde. Infelizmente, eu trabalho na área da Saúde, mas eu sinto também a falta. Uma dificuldade, a falta de capacitação para o trabalho. As dificuldades que a gente tem são essas (ACS).

A necessidade de ter dinheiro, apontada pelos sujeitos da pesquisa, reitera, por outra via, a questão das más condições de vida como problema de saúde. Isso porque, numa civilização do capital como a nossa, em que o dinheiro assume a condição de mercadoria universal pela qual todas as outras podem ser trocadas ${ }^{28}$, e num contexto em que o Estado não consegue garantir os direitos sociais e deixa para o mercado a possibilidade de transformá-los em mercadoria, a falta monetária impede a "compra" daquilo que se julga precisar para ter uma boa vida, com todas as implicações que isso tem para a saúde. Você sabe que, hoje em dia, para você ter uma boa qualidade de vida, você tem que ter dinheiro (ACS).

O cenário de fragilidades pode contribuir para a propagação da ideologia de que a instalação do Perímetro Irrigado Santa Cruz do Apodi irá trazer o desenvolvimento para a população. No entanto, esse mito pode ser superado com os resultados de estudo que demonstram que a implantação de perímetros irrigados e do agronegócio no Baixo Jaguaribe, no Ceará, não proporcionaram melhoria nas condições de vida. Ao contrário, verificaram-se problemas em moradias, precarização do trabalho, problemas de saúde decorrentes dos agrotóxicos, contaminação da água ${ }^{11}$.

Outro aspecto observado diante da omissão do Estado em relação às condições de vida das comunidades camponesas é a prática do clientelismo. Quer dizer, aquilo que o Estado tem obrigação de fazer para a população é convertido em favor, posteriormente, trocado pelo apoio político em tempos de campanhas eleitorais locais: Para conseguir um poço para a gente, foi através de uma politicagem e grande (Camponeses).

É interessante considerar que, por mais que os camponeses vivam um contexto de vulnerabilidade decorrente da sociedade capitalista atual, eles, a partir de práticas vivenciadas e compartilhadas, constroem identidades, modos de vida próprios, lutas sociais coletivas (...), dando sustentação a seus projetos político-pedagógicos ${ }^{29}$.

\section{Necessidade de mobilização social}

As necessidades de saúde, como expressão histórica de movimentos que assumem como iníquas certas condições sociais, podem impulsionar a mobilização social na medida em que as carências comprometem, motivam e mobilizam as pessoas. Em outras palavras, os indivíduos percebem, manifestam as condições sociais e políticas que os oprimem e lutam para enfrentá -las ${ }^{17}$. Isso fica evidente na conjuntura de conflito ambiental analisado. Nela, movimentos sociais e comunidades camponesas, atingidas pelo projeto de irrigação, percebem as iniquidades sociais nesse processo e reivindicam, mediante grande mobilização social no campo, tanto a manutenção da forma de viver e trabalhar na agricultura familiar agroecológica quanto o incentivo a esta. Pode-se dizer, assim, que a percepção de uma necessidade de saúde está atrelada à visão de mundo dos indivíduos.

"Qualquer carência é simbolicamente referida aos valores fundamentais partilhados pelos indivíduos, aos direitos e obrigações legitimamente estabelecidos; imediatamente, pois, uma dada compreensão da realidade e da desigualdade social emerge com a percepção de uma carência" ${ }^{\prime 17}$.

A necessidade de mobilização social está inter-relacionada à de revisão do modelo de desenvolvimento agrário, de ter boas condições de vida e de evitar o uso de agrotóxicos. Faz parte ainda da história dos camponeses de Apodi-RN, marcada por lutas e conquistas de movimentos sociais no campo, em defesa da agricultura familiar camponesa. Destacam-se como sujeitos coletivos o STTR, o Fórum dos Agricultores Familiares de Apodi, a CPT e o Movimento das Mulheres. As principais ações de resistência ao perímetro irrigado/agronegócio/agrotóxicos que vêm sendo realizadas pelos movimentos sociais estão relacionadas à formação e difusão de informações entre os atingidos, à pressão sobre autoridades públicas, a manifestações públicas e articulação 
em redes estaduais e nacionais ${ }^{18}$. É importante salientar que essa luta não acontece de forma isolada, mas está articulada a mobilizações nacionais, como a Campanha Permanente Contra os Agrotóxicos e Pela Vida, o Fórum Nacional de Combate aos Efeitos dos Agrotóxicos e o Livro Dossiê Abrasco: um alerta sobre os impactos dos agrotóxicos na saúde ${ }^{9}$.

A experiência vivenciada pelas comunidades camponesas permite-lhes uma compreensão crítica do contexto em que vivem, que as fazem reconhecer as desigualdades sociais do processo em curso e as mobilizam a lutar por seus ideais, por suas necessidades. Soma-se ainda o entendimento dos camponeses e dos movimentos sociais de que, no Estado contraditório capitalista, a mobilização social é fundamental, para que os camponeses consigam atender suas necessidades, já que o Estado não as reconhece. Por exemplo, "quando se trata de problemas de saúde relacionados à qualidade das forças produtivas, das tecnologias e de seu impacto no meio ambiente, o Estado tende a selecionar negativamente as necessidades de saúde expressas pela população" ${ }^{17}$.

Nesse cenário de atuação de camponeses e movimentos sociais, foi comunicada na pesquisa a necessidade de se mobilizarem as pessoas das comunidades para evitar a instalação do projeto de irrigação:

É conscientizar o pessoal para evitar que eles deem o apoio a isso que vem acontecendo por aí. Por isso eu converso muito com o povo. Vamos ter consciência que esse projeto [de irrigação] não vem para beneficiar a gente. E, quando ele se implantar, aí, ninguém tira mais. Porque não somos nós quem manda; quem está mandando são eles, os empresários, que vêm tirar o povo de dentro das suas propriedades e jogar uma empresa, produzindo convencional com veneno, com avião jogando [veneno] por cima e tudo (Camponeses). (Grifos nossos).

$\mathrm{Na}$ fala acima, identifica-se a percepção dos sujeitos locais da existência da assimetria de poderes e da mobilização como forma de construir força política. Em resumo, "a definição das necessidades de saúde da população resulta de um processo histórico que supera os limites impostos pelo Estado à ação social dos indivíduos”17.

\section{Necessidade de evitar os agrotóxicos}

Entre os agravos à saúde relacionados ao agronegócio, os de maior relevância e impacto negativo para a saúde humana e ambiental são as poluições e/ou contaminações e intoxicações agudas e/ou crônicas relacionadas aos agrotóxicos.
Desde 2008, o Brasil ocupa o lugar de maior consumidor de agrotóxicos do mundo, com amplos impactos na saúde pública, atingindo vastos territórios e envolvendo diferentes grupos populacionais ${ }^{9}$. Isso reforça a importância da necessidade de evitar os agrotóxicos.

A utilização de agrotóxicos tem como implicações intoxicações e efeitos crônicos que podem ser expressos em distúrbios dos sistemas nervoso, respiratório, digestivo, reprodutor, na pele, em cânceres, entre outros ${ }^{30}$. A exposição humana aos agrotóxicos pode ocorrer pela ingestão de alimentos contaminados; por inalação direta ou contato com a pele, especialmente, no caso dos trabalhadores e de pessoas residentes em áreas próximas a cultivos; consumo de água contaminada oriunda de rios, lagos, poços, sistemas de abastecimento e outras fontes de água potável com presença de agrotóxicos 9 .

Alguns grupos sociais são mais vulneráveis, tais como os trabalhadores que plantam, vendem, transportam, manipulam/pulverizam esses insumos e, indiretamente, suas famílias, que moram dentro das plantações e higienizam suas roupas e Equipamentos de Proteção Individual (EPI), além do contato através do armazenamento desses produtos dentro ou próximo de suas residências ${ }^{30}$; e crianças, seja pela exposição direta ou consumo de leite materno e outros alimentos contaminados. Diante disso, é preciso ampliar a atuação do Estado e da sociedade no controle do uso de agrotóxicos ${ }^{9}$.

$\mathrm{Na}$ pesquisa, emergiu a necessidade de se ensinarem os camponeses a não usar agrotóxicos desde a infância, no espaço escolar, focando-se o risco dessas substâncias para a saúde e o ambiente.

Eu acho que uma coisa que deveria ser feita é conversar essa questão dos agrotóxicos de uma forma pedagógica legal, com as crianças mesmo. A criança, ela vai aprendendo e desenvolvendo que aquilo é ruim. E eu acho que, nessas escolas infantis, lá nas comunidades que vocês (ACS) atuam, isso é possível, discutir essas questões dos agrotóxicos. Então, é uma coisa que as mudanças são lentas, mas são muito necessárias. E começar na sala de aula, com os filhos de agricultor e agricultoras pequenininhos, isso vai ser mais fácil. Dessa forma, a gente tem uma resistência para o agronegócio entrar lá (Movimentos Sociais).

O grupo de pesquisa trouxe que a necessidade de evitar os agrotóxicos contribui para prevenção de doenças, e isso está diretamente relacionado às atividades do SUS, em especial, da ESF, isto é, realizar ações que descortinem os impactos dos 
agrotóxicos para a saúde, o que pode ser feito através da educação em saúde e da territorialização em saúde.

O que a gente poderia fazer, para que o povo deixasse de usar e de comer veneno? A prevenção. Por exemplo, o filme 'O veneno está na mesa', se a gente pudesse, assim, numa ação bem concreta, se a gente pudesse levar para a equipe do Programa Saúde da Família, e só passar o filme e fazer uma discussão, eu acho que iria ajudar muito a vocês e à comunidade esclarecer essas questões do risco (Movimentos Sociais).

Todas as necessidades de saúde discutidas até agora remetem à atuação do SUS e requerem a intersetorialidade com as demais políticas públicas, o que chama atenção para que o sistema de saúde, a partir da identificação dessas necessidades, procure se articular com os demais setores e atores, para intervir de maneira positiva sobre essa realidade.

\section{Necessidade de atuação do SUS}

A necessidade de atuação do SUS frente à saúde dos camponeses surge diante de problemas verificados no acesso aos serviços de saúde, nas atenções básicas, especializadas e hospitalares, na vigilância e promoção da saúde e na prevenção de doenças e agravos que acometem essa população. A extensão e magnitude desses problemas expõem que a discrepância entre as proposições do SUS e sua execução é ainda maior no campo do que na cidade.

A maior dificuldade que a gente enfrenta, por exemplo, a gente trabalha na agricultura e, quando a gente precisa, a gente vai para o hospital e não tem assistência nenhuma. Isso é uma dificuldade que a gente enfrenta. Nós temos problemas de saúde e somos tratados como se fossem uns cachorros (Camponeses).

Os problemas referidos à gestão municipal de saúde englobam a racionalização dos gastos com saúde e a precarização do trabalho na ESF. Na Atenção Básica, falta estrutura física para se trabalhar, o que tem sido apontado ainda em outros estudos $^{31}$, pois, em muitas comunidades rurais, não há "postos de saúde". Nas poucas localidades rurais do município onde existem, eles servem como ponto de apoio para outras mais próximas. Por isso os atendimentos são realizados em locais improvisados e/ou adaptados, que "restringem drasticamente o escopo das ações com o comprometimento de sua qualidade técnico-científica" ${ }^{31}$. Soma-se, além disso, a falta de materiais, como medicamentos, material de expediente, de lim- peza, fardamento, balanças, transporte dos ACS e da equipe.

No âmbito dos processos de trabalhos, observam-se dificuldades de trabalho em equipe, falta de vínculo entre ESF e comunidade, ênfase em ações ambulatoriais, incipiência de ações de prevenção de doenças, que se resumem, quando muito, àquelas programáticas do Ministério da Saúde, e a quase inexistência de ações de promoção da saúde e vigilância à saúde.

Esses problemas no trabalho em equipe da ESF, somados às precárias condições de trabalho, repercutem diretamente na oferta e qualidade dos serviços dirigidos às comunidades camponesas e, consequentemente, na capacidade de respostas do SUS para atender às demandas e necessidades de saúde.

A realidade da ESF, na pesquisa, mostra ações que se resumem à prática ambulatorial, com demanda espontânea, o que está muito distante dos objetivos da estratégia, e reforça as evidências que apontam a persistência dos antigos modelos de atenção à saúde, em detrimento da reorientação do modelo assistencial ${ }^{32-34}$. As ações de prevenção e promoção da saúde deixam a desejar. Além disso, no momento investigado, a equipe funciona com cada profissional realizando a assistência individual, com seu saber fragmentado.

Nas atenções secundária, terciária e hospitalar, foram referidos falta de atendimento médico especializado, de equipamentos e um sistema de referência e contrarreferência deficiente, reiterando problemas já explicitados na literatura, decorrentes de insuficiências financeiras, de gestão, de regulação, de relações entre os subsistemas público e privado, e de organização interna do sistema de saúde ${ }^{35}$.

\section{Respostas às necessidades de saúde de camponeses: universidade, SUS e movimentos sociais construindo juntos um plano de ação}

Em resposta às necessidades e problemas de saúde verificados, o grupo de pesquisa construiu um plano de ação para o enfrentamento de problemas prioritários e definiu nele os responsáveis por ação, conforme o Quadro 2.

O diálogo entre universidade, SUS e movimentos sociais promoveu troca de experiências, que possibilitou o reconhecimento de necessidades de saúde que requerem a intersetorialida$\mathrm{de}^{36}$. As ações contidas no plano contemplam a promoção da saúde, prevenção de doenças, vigilância à saúde, assistência, participação popular 
Quadro 2. Plano de Ação como resposta às necessidades de saúde de camponeses, construído pelo grupo de pesquisa $^{18}$.

\begin{tabular}{|c|c|c|}
\hline $\begin{array}{c}\text { Problemas e necessidades } \\
\text { de Saúde }\end{array}$ & Ações & Responsáveis \\
\hline $\begin{array}{l}1 \text { Atuação da ESF com } \\
\text { "olhar" em Saúde do } \\
\text { Trabalhador (ST). }\end{array}$ & $\begin{array}{l}\text { - Capacitação continuada da Atenção Básica nos } \\
\text { protocolos de atenção à ST. }\end{array}$ & CEREST Regional. \\
\hline $\begin{array}{l}2 \text { Fortalecer as ações de } \\
\text { vigilância à saúde. }\end{array}$ & $\begin{array}{l}\text { - Criar vínculo entre a Vigilância à Saúde do } \\
\text { município e o CEREST Regional. } \\
\text { - Identificar fragilidades e propor melhorias na } \\
\text { atuação prática. } \\
\text { - Articular Vigilância à Saúde municipal com } \\
\text { ESF. }\end{array}$ & $\begin{array}{l}\text { CEREST e Vigilância à Saúde } \\
\text { do município. }\end{array}$ \\
\hline $\begin{array}{l}3 \text { Uso do veneno pela } \\
\text { agricultura familiar. }\end{array}$ & $\begin{array}{l}\text { - Campanha permanente contra o agrotóxico } \\
\text { (exibição de documentário). } \\
\text { - Reuniões de conscientização. } \\
\text { - Oficina com a comunidade rural, para } \\
\text { conscientizar sobre os riscos dos agrotóxicos. } \\
\text { Oficina de } 8 \mathrm{~h} \text {. }\end{array}$ & $\begin{array}{l}\text { Sindicato dos Trabalhadores } \\
\text { Rurais, Comissão Pastoral } \\
\text { da Terra (CPT) e associações } \\
\text { comunitárias. } \\
\text { CEREST Regional, } \\
\text { universidade, ESF e } \\
\text { sindicatos. }\end{array}$ \\
\hline $\begin{array}{l}4 \text { Uso de venenos agrícolas } \\
\text { nos projetos de irrigação já } \\
\text { existentes, de empresas do } \\
\text { agronegócio. }\end{array}$ & $\begin{array}{l}\text { - Atuação direta nas áreas em que há projetos } \\
\text { instalados: visita de inspeções sanitárias e } \\
\text { das condições de trabalho nas empresas do } \\
\text { agronegócio. } \\
\text { - Articulação com os trabalhadores assalariados } \\
\text { do agronegócio. }\end{array}$ & $\begin{array}{l}\text { CEREST, PSF e } \\
\text { Sindicato dos Trabalhadores } \\
\text { Rurais. }\end{array}$ \\
\hline $\begin{array}{l}5 \text { Projeto de Irrigação } \\
\text { proposto pelo DNOCS. }\end{array}$ & $\begin{array}{l}\text { - Campanha de denúncia/esclarecimento para a } \\
\text { sociedade. } \\
\text { - Construção de proposta alternativa. } \\
\text { - Mobilizações. } \\
\text { - Acompanhamento jurídico aos atingidos. }\end{array}$ & $\begin{array}{l}\text { STR, CPT, Fórum do Campo } \\
\text { Potiguar (FOCAMPO) e } \\
\text { outros. } \\
\text { Universidades. } \\
\text { STR, CPT, Rede Nacional } \\
\text { dos Advogados Populares } \\
\text { (RENAP) e FOCAMPO } \\
\end{array}$ \\
\hline $\begin{array}{l}6 \text { Aumento de problemas } \\
\text { respiratórios. }\end{array}$ & $\begin{array}{l}\text { - Mobilização de conscientização da população } \\
\text { sobre a relação entre as doenças respiratórias e as } \\
\text { emissões (fumaça, pós) das caeiras. } \\
\text { - Direitos trabalhistas. }\end{array}$ & $\begin{array}{l}\text { SUS, Secretaria de Saúde, } \\
\text { Centro de Referência em } \\
\text { Assistência Social (CRAS) } \\
\text { e equipe local, movimentos } \\
\text { sociais. }\end{array}$ \\
\hline 7 Má distribuição de água. & - Reunir a comunidade para discutir o problema. & Comunidade e parceiros. \\
\hline 8 Casas de taipa. & $\begin{array}{l}\text { - Comunidade se organizar para buscar solução } \\
\text { do problema. }\end{array}$ & $\begin{array}{l}\text { Fundação Nacional de } \\
\text { Saúde (FUNASA), Prefeitura } \\
\text { Municipal, comunidades, } \\
\text { movimentos sociais. } \\
\end{array}$ \\
\hline $\begin{array}{l}9 \text { Quantidade insuficiente de } \\
\text { escolas públicas. }\end{array}$ & $\begin{array}{l}\text { - Acionar os gestores do município, do Estado e } \\
\text { promotoria pública. }\end{array}$ & As comunidades. \\
\hline 10 Falta de estradas. & $\begin{array}{l}\text { - Reunião com o secretário de obras e as } \\
\text { comunidades. }\end{array}$ & Sociedade civil. \\
\hline $\begin{array}{l}11 \text { Falta de conhecimento } \\
\text { dos trabalhadores com } \\
\text { relação à Saúde do } \\
\text { Trabalhador e Saúde } \\
\text { Ambiental. }\end{array}$ & $\begin{array}{l}\text { - Expor aos trabalhadores o conhecimento } \\
\text { com relação à Saúde do Trabalhador e Meio } \\
\text { Ambiente. }\end{array}$ & $\begin{array}{l}\text { SUS, CEREST, universidade, } \\
\text { sindicato e movimentos } \\
\text { sociais. }\end{array}$ \\
\hline
\end{tabular}

e educação em saúde. Buscam, com um caráter intersetorial e interdisciplinar, a satisfação de necessidades de revisão do modelo de desenvolvimento agrário, de boas condições de vida, de 
atuação do SUS, de evitar os agrotóxicos e de mobilização social.

Com base nesse plano, pode-se dizer que o grupo tem uma visão ampliada de saúde, que não se limita à ausência de doenças. $\mathrm{O}$ projeto de irrigação visto como um problema de saúde e sua não instalação como necessidade de saúde são exemplos disso, já que estão em pauta essas questões de ordem estrutural, como o modelo de desenvolvimento que se quer para os territórios camponeses, que trazem implicações para o modo de viver e trabalhar e para o processo saúde-doença individual/coletivo dos agricultores familiares. Nessa perspectiva, as ações construídas de campanha de denúncia/esclarecimento para a sociedade, mobilizações, construção de proposta alternativa e acompanhamento jurídico aos atingidos caracterizam-se como de promoção da saúde e apontam a importância de uma educação em saúde problematizadora, que descortine a realidade.

\section{Considerações finais}

A partir das articulações construídas no território, o diálogo entre universidade e movimentos sociais vem sendo fortalecido, sobretudo com grupos de pesquisa de universidades públicas, comprometidos com a transformação social, que inserem o conflito ambiental em pesquisa, extensão e ensino. Agora, a continuidade de discussões e ações com o SUS é um desafio.
As possibilidades de aproximar o SUS do plano estratégico construído devem ser percebidas nos diversos cenários sociais, permeados por conflitos de interesses. Os ACS terem protagonizado nas ESF debates a partir do documentário "O veneno está na mesa" e a realização de levantamento dos camponeses do território expostos a agrotóxicos já produziram tensões na equipe para o reconhecimento e ação diante das necessidades de saúde do território, o que não aconteceu com o CEREST regional, que ficou inerte.

O SUS precisa compreender as necessidades de saúde no contexto sócio-histórico em que os sujeitos individuais e coletivos se inserem. Podem contribuir para isso a territorialização em saúde, com a construção de mapas participativos em diálogo com as comunidades dos territórios, a inserção/fortalecimento de ações de saúde do trabalhador e saúde ambiental nos serviços.

\section{Colaboradores}

AGV Pontes trabalhou na concepção da pesquisa, coleta e análise das informações, construção e revisão do artigo. RM Rigotto orientou toda a pesquisa e participou da construção e revisão crítica do artigo. JV Silva trabalhou na construção e revisão do artigo. 


\section{Referências}

1. Rigotto RM, Augusto LGS. Saúde e Ambiente no Brasil: desenvolvimento, território e iniqüidade social. Cad Saude Publica 2007; 23(Supl.):s475-s485.

2. Rigotto RM. Caiu na rede, é peixe!: a industrialização tardia e suas implicações sobre o trabalho, o ambiente e a saúde. Cad Saude Publica 2007; 23(Supl.):s599-s611.

3. Miranda AC, Tambellini AT, Moreira JC. As relações entre o modelo de desenvolvimento e os impactos sobre o ambiente e a saúde humana: uma revisão do cenário atual. Cad Saúde Colet (UFRJ) 2011; XIX:249249.

4. Porto MF, Milanez B. Eixos de desenvolvimento econômico e geração de conflitos socioambientais no Brasil: desafios para a sustentabilidade e a justiça ambiental. Cien Saude Colet 2009; 14(6):1983-1994.

5. Elias D. Agronegócio e desigualdades socioespaciais. In: Elias D, Pequeno R, organizadores. Difusão do agronegócio e novas dinâmicas socioespaciais. Fortaleza: Banco do Nordeste do Brasil; 2006. p. 25-82.

6. Rigotto RM, Teixeira ACA. Desenvolvimento e sustentabilidade socioambiental no campo, na cidade e na floresta. In: Caderno de Textos da I Conferência Nacional de Saúde Ambiental; 2009, Brasília. p. 78-83.

7. Fernandes BM, Welch CA. Campesinato e agronegócio da laranja nos EUA e Brasil. In: Fernandes BM, organizador. Campesinato e agronegócio na América Latina: a questão agrária atual. São Paulo: Expressão Popular; 2008. p. 45-70.

8. Silva JM, Silva EM, Faria HP, Pinheiro TMM. Agrotóxico e trabalho: uma combinação perigosa para a saúde do trabalhador rural. Cien Saude Colet 2005; 10(4):891903.

9. Carneiro FF, Augusto LGS, Rigotto, RM, Friedrich K, Búrigo AC, organizadores. Dossiê Abrasco: um alerta sobre os impactos dos agrotóxicos na saúde. São Paulo: Expressão Popular; 2015.

10. Dantas BL, Liberalino Filho J, Lira JFB de, Maracajá PB, Diniz Filho ET. A agroecologia nos assentamentos de Moacir Lucena, Sítio do Góis e Vila Nova em Apodi -RN. Infotecnarido 2007; 1(1):1-12. [acessado 2011 jun 15]. Disponível em: http://revista.gvaa.com.br.

11. Pontes AGV, Gadelha D, Freitas BMC, Rigotto RM, Ferreira MJM. Os perímetros irrigados como estratégia geopolítica para o desenvolvimento do semiárido e suas implicações à saúde, ao trabalho e ao ambiente. Cien Saude Colet 2013; 18(11):3213-3222.

12. Rigotto RM, Freitas BMC. Dossiê Perímetros Irrigados. Perímetros irrigados e a expansão do agronegócio no campo: quatro décadas de violação do direito no semiárido. [acessado 2014 jun 15]. Disponível em: http:// dossieperimetrosirrigados.net/

13. Zhouri A, Laschefski K. Desenvolvimento e conflitos ambientais: um novo campo de investigação. In: Zhouri A, Laschefski K, organizadores. Desenvolvimento e conflitos ambientais. Belo Horizonte: UFMG; 2010. p. 11-33.

14. Mendes-Gonçalves RB. Práticas de saúde: processos de trabalho e necessidades. São Paulo: Secretaria Municipal da Saúde; 1992.

15. Heller A, Fehér F. A condição política pós-moderna. Rio de Janeiro: Civilização Brasileira; 2002.

16. Vale-Silva J. Necessidades de saúde: subsídios ao pensar/ fazer saúde [dissertação]. Fortaleza: Universidade Federal do Ceará; 2012.
17. Stotz EM. Necessidades de saúde: mediações de um conceito [tese]. Rio de Janeiro: Escola Nacional de Saúde Pública; 1991.

18. Pontes AGV. Saúde do Trabalhador e Saúde Ambiental: articulando universidade, SUS e movimentos sociais em território rural [dissertação]. Fortaleza: Universidade Federal do Ceará; 2012.

19. Minayo MCS. O desafio do conhecimento: pesquisa qualitativa em saúde. 12a ed. São Paulo: Hucitec; 2010

20. Thiollent M. Metodologia da pesquisa-ação. 16ª ed. São Paulo: Cortez; 2008.

21. Rosen G. Da política médica a medicina social. Rio de Janeiro: Graal; 1979.

22. Scliar M, Almeida Filho N, Medronho R. Raízes históricas da Epidemiologia. In: Almeida Filho N, Barreto ML. Epidemiologia e Saúde: fundamentos, métodos e aplicações. Rio de Janeiro: Guanabara Koogan; 2012. p. 5-23.

23. Breilh J. Epidemiologia: economia, politica e saúde. São Paulo: UNESP, Hucitec; 1991.

24. Laurell ACA. Saúde-doença como processo social. Rev Latinoam de Salud 1982; 2:7-25.

25. Paim JS, Almeida Filho N. Saúde coletiva: uma "nova saúde pública" ou campo aberto a novos paradigmas? Rev Saúde Publica 1998; 32(4):299-316.

26. Paim JS. Reforma Sanitária Brasileira: contribuição para a compreensão e crítica. Salvador: Edufba; Rio de Janeiro: Fiocruz; 2008.

27. Brasil. Ministério da Saúde (MS). Política Nacional de Saúde Integral das Populações do Campo e da Floresta. Brasília, 2008. [acessado 2012 Set 2]. Disponível em: http://www.saude.ba.gov.br/dab/images/stories/Documentos/cer/PNSIPCF_Revisada_CIT_19_11_2008.pdf

28. Marx K. Para a crítica da economia política; salário, preço e lucro; o rendimento e suas fontes: a economia vulgar. São Paulo: Abril Cultural; 1982.

29. Vazquez OS, Souza MS. Controle social e mobilização pelo direito à saúde das populações do campo e floresta. Brasília: Contag; 2011.

30. Pignati WA, Machado JMH, Cabral JF. Acidente rural ampliado: o caso das "chuvas" de agrotóxicos sobre a cidade de Lucas do Rio Verde-MT. Cien Saude Colet 2007; 12(1):105-114.

31. Uchoa AC, Souza EL, Spinelli AFS, Medeiros RG, Peixoto DCS, Silva RAR, Rocha NSP. Avaliação da satisfação do usuário do Programa de Saúde da Família na zona rural de dois pequenos municípios do Rio Grande do Norte. Physis 2011; 21(3):1061-1076.

32. Camargo Júnior KR, Campos EMS, Bustamante-Teixeira MT, Mascarenhas MTM, Mauad NM, Franco TB, Ribeiro LC, Alves MJM. Avaliação da atenção básica pela ótica político-institucional e da organização da atenção com ênfase na integralidade. Cad Saude Publica 2008; 24(Supl. 1):58-68.

33. Giovanella L, Mendonça MHM, Almeida PF, Escorel S, Senna MCM, Fausto MCR, Delgado MM, Andrade CLT, Cunha MS, Martins MIC, Teixeira CP. Saúde da família: limites e possibilidades para uma abordagem integral de atenção primária à saúde no Brasil. Cien Saude Colet 2009; 14(3):783-794 
34. Rocha PM, Uchoa AC, Rocha NSPD, Souza ECF, Rocha ML, Pinheiro TXA. Avaliação do Programa Saúde da Família em municípios do Nordeste brasileiro: velhos e novos desafios. Cad Saude Publica 2008; 24(Sup1.):6978.

35. Paim J, Travassos C, Almeida C, Bahia L, Macinko J. O sistema de saúde brasileiro: história, avanços e desafios. Lancet 2011; Publicado on line em 9 de maio.

36. Andrezza GVP, Rigotto RM. Saúde do Trabalhador e Saúde Ambiental: potencialidades e desafios da articulação entre universidade, SUS e movimentos sociais. Rev. bras. Saúde ocup. 2014; 39(130):161-174.

Artigo apresentado em 12/09/2014

Aprovado em 25/07/2016

Versão final apresentada em 27/07/2016 